\title{
Study on a New Technique to Prevent the Shrinkage defects of Alloy Ductile Iron Crankshaft
}

\author{
LIU Zhaoming \\ School of Materials Science and Engineering \\ Dalian Jiaotong University \\ Dalian City, Liaoning Province, China \\ lzm100@163.com
}

\author{
LIU Xiaoyan \\ School of Materials Science and Engineering \\ Dalian Jiaotong University \\ Dalian City, Liaoning Province, China \\ 056329shenfei@sina.com
}

\begin{abstract}
Self-developed shrinking eliminating agent for alloy crankshaft was used to crankshaft specimen with dispersed shrinkage, changing the package materials, the composition and the amount of addition of the shrinking eliminating agent, macroscopical and microcosmic analyses of the section were performed to optimize the effect with the comparison. The results show that the better package material is the gray cast iron which melts completely in molten iron during casting. When the addition of eliminating shrinking agent No.3 is $6 \mathrm{~g}$, the shrinkage defects of crankshaft specimen can be eliminated completely. After adding shrinking eliminating agent, no abnormal graphite appears, the amount of spheroidal graphite increases and the sphere diameter reduces.
\end{abstract}

Keywords: nodular iron; shrinkage; shrinking eliminating agent; new technique

\section{INTRODUCTION}

Shrinkage and dispersed shrinkage are the most common casting defects of ductile iron, which are the key factors influencing the quality of casting [1]. From the test results, shrinkage often appears in the solidifying location finally of the crankshaft, such as the hot spots of crankshaft, that is the joints of crankshaft balance block and the shaft neck, crank arm and shaft neck, which are the holes connecting interior with exterior of crankshaft. The holes inwall are generally rough relatively, sometimes crystals in developing dendrite can be seen attached to the inner surface of the holes[2].

Due to the "mushy solidification" feature of ductile iron[3], as well as the complexity of shrinkage, shrinkage porosity formation, shrinkage is the inherent defect and it is difficult to completely eliminate by the traditional treatment process. There are many inconsistent or even contradictory views on formation mechanism and preventing emasures of shrinkage and dispersed shrinkage [4 6] which are confused. How to eliminate the shrinkage and dispersed shrinkage defects of nodular cast iron has been the research topic of foundry workers.

Adding cold iron and other methods often are used in production to drive the shrinkage to internal, which cause the defect disappeared on the surface. But with the progress of science and technology, customers' demand for casting quality is improving. Non Destructive Testing is usually performed to expose the defect. Therefore, how to use a new process to solve completely the shrinkage defects of nodular iron crankshaft has become the common concern of manufacturers, which has significantly theoretical and practical value. Self-developed shrinking eliminating agent for nodular cast iron was used to defective part of crankshaft specimen with dispersed shrinkage, by changing the growth mode of regional ductile iron and refining grains during solidification, to reduce or eliminate the shrinkage defects in the region.

\section{EXPERIMENTAL MATERIAL AND METHOD}

The copper, tin and gray cast iron are used to contain and fix shrinking eliminating agents. The shrinking eliminating agent is cut to granule length of $2 \mathrm{~mm}$ and divided into four groups, as shown in table 1. QT800-2 liquid iron is used to form casting crankshaft, the main chemical composition of molten iron is shown in table 2.

TABLE 1. EXPERIMENTAL MATERIAL

\begin{tabular}{cc}
\hline Samples & Action principle \\
\hline No.1 & Promote the graphite precipitation \\
No.2 & Grain refinement \\
No.3 & Anti-graphitization,Grain refinement \\
No.4 & Increasing incubation \\
\hline
\end{tabular}

TABLE 2. COMPOSITION OF TESTED LIQUID IRON

\begin{tabular}{ccccccccc}
\hline $\mathrm{C}$ & $\mathrm{Si}$ & $\mathrm{Mn}$ & $\mathrm{Mg}$ & $\mathrm{S}$ & $\mathrm{P}$ & $\mathrm{Cu}$ & $\mathrm{Mo}$ & $\mathrm{RE}$ \\
\hline $3.5-4.0$ & $1.8-2.8$ & $0.3-0.6$ & $0.02-0.1$ & $\leq 0.025$ & $\leq 0.08$ & $0.5-1.0$ & 0.42 & 0.01
\end{tabular}

Shrinking eliminating agents with different materials coating before casting are fixed to the specified location of the crankshaft model prone to shrinkage. The crankshaft specimen is cast at the temperature of $1320-1360{ }^{\circ} \mathrm{C}$. After annealing treatment, macroscopical and microcosmic analyses on the cross-section are performed.

\section{RESUlTS AND DISCUSSION}

\section{A. Analysis of Different Wrapping Materials}

Three specimens are cast with No.3 shrinking eliminating agent, whose wrapping materials are copper, tin and gray cast iron respectively. Anatomical sections of these specimens are shown in Figure 1.

1) Shrinking eliminating agents with copper coated can promote the graphitization in the eutectic transformation and strengthen the matrix. Specimens are cut after casting and cooling. As is shown there is a piece of residual copper 
floating in the specimen surface, which indicated the copper could not completely fuse with liquid iron with casting and caused the pollution of casting.

2) There is residue on the surface of specimen with tinplate package. Shrinking eliminating agents could not give the full play since the package had not melted completely.
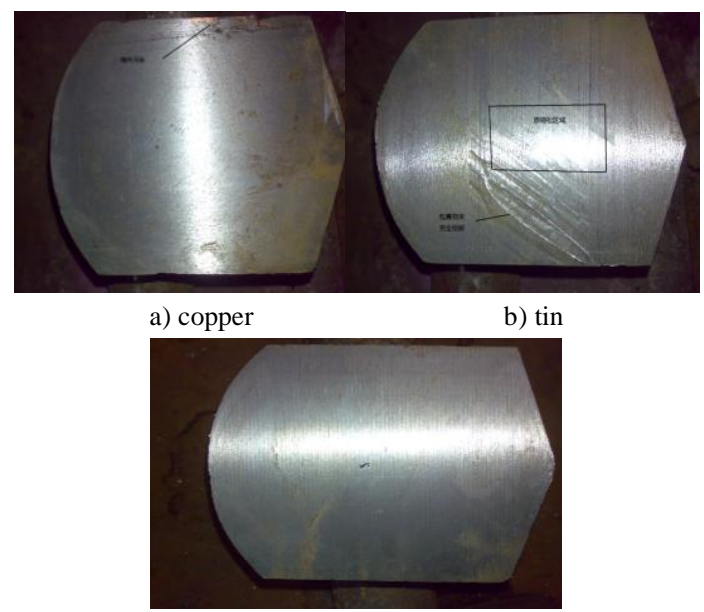

c) gray cast iron

Figure 1.

3) With HT150 coating material, on the one hand no other alloy element can be introduced which effects graphite morphology or contaminates samples, on the other hand, the grey cast iron contains graphite, which promotes the graphite precipitation and reduces the shrinkage defects. In addition, the gray cast iron play a role of micro internal chill. The grey cast iron is suitable for wrapping material.

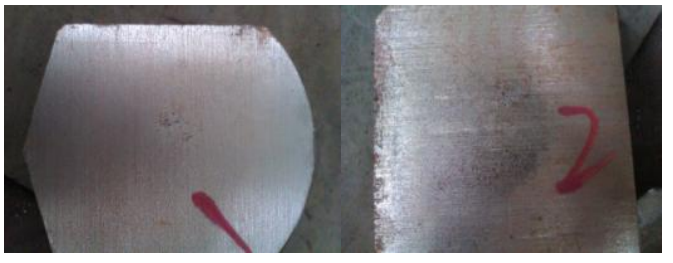

a) No. 1

b) No. 2

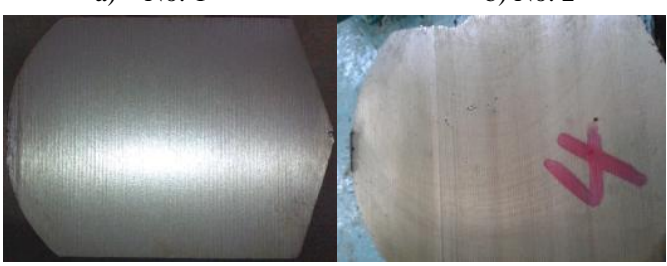

c) No. 3

d) No. 4

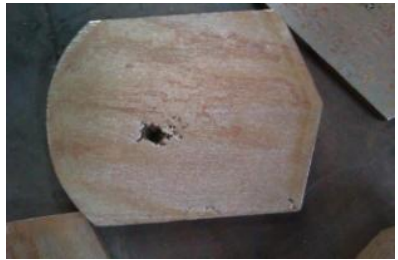

e) contrast

Figure 2. The crankshaft specimen with different additions of shrinkage eliminating agent

\section{B. Influence of Different Composition of Shrinking Eliminating} Agents

The crankshaft specimens are respectively added in different components of shrinking eliminating agents No. 1 , No. 2, No. 3, No. 4, no additive as a reference, anatomical sections of these specimens are shown in Figure 2. There are serious shrinkage defects in the reference. Adding shriking eliminating agents reduces the defects to a large extent. As is shown, adding No.3 can eliminate completely the shrinkage defects of crankshaft.

\section{Influence of Different Amount of Shrinking Eliminating Agents}

The crankshaft specimens are respectively added in different amount of shrinking eliminating agents $4 \mathrm{~g}, 6 \mathrm{~g}, 10 \mathrm{~g}$, which are cut after casting, as is shown in Fig. 3. The shrinkage defects of crankshaft eliminate completely when the addition is $6 \mathrm{~g}$. Adding $10 \mathrm{~g}$ shriking eliminating agents reduces the defects to a large extent. It illustrates that the addition of shriking eliminating agents makes important influence.

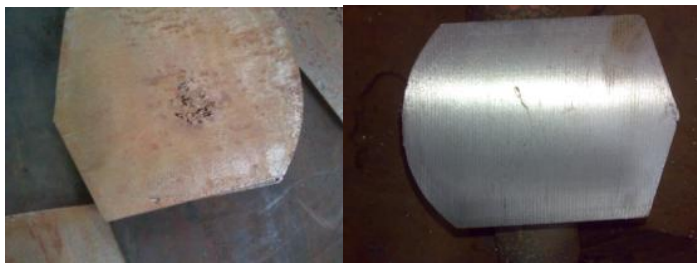

a) $4 g$ b) $6 \mathrm{~g}$

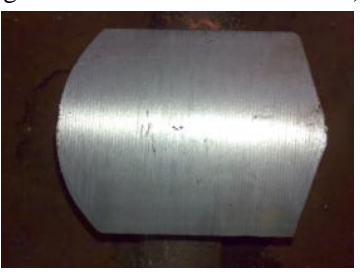

c) $10 \mathrm{~g}$

Figure 3. The crankshaft specimen with different amount of shrinkage eliminating agent

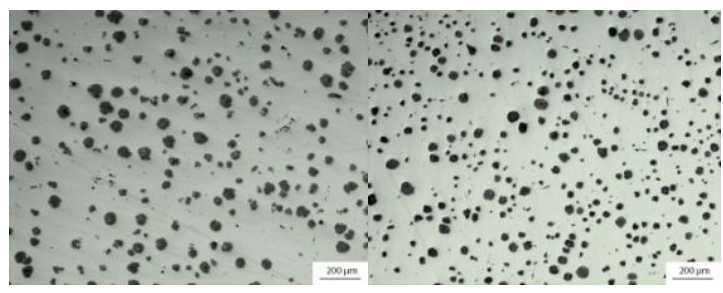

a) contrast

b) $6 \mathrm{~g}$

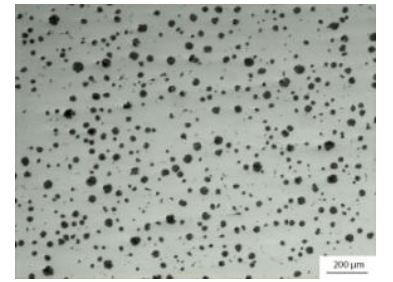

c) $10 \mathrm{~g}$

Figure 4. Micrographic of graphitespher oidalization grades and graphite size classification 


\section{Influence of Graphite Morphology, Quantity and Size of} Ductile Iron Crankshaft.

The crankshaft specimens are respectively added No.3 shrinking eliminating agents in different amount of $6 \mathrm{~g}, 10 \mathrm{~g}$, no additive as a reference. According to GB/ T9441-2009 nodular cast iron metallographic inspection standards, the original specimen graphite morphology is spherical graphite, nodulizing grade was level 2. After adding No.3 shrinking eliminating agents, no abnormal graphite appears, graphite nodulizing grade was still level 2 , the number of graphite increases significantly, and the ball diameter is smaller, as is shown in Fig. 4.

\section{CONCLUSIONS}

1. HT150 is more suitable for package material of shrinking eliminating agents compared with copper and tin.

2 . The composition of shrinking eliminating agents play an important role to reduce or completely eliminate the shrinkage defects of crankshaft specimens. Adding No.3 can eliminate completely the shrinkage defects of crankshaft.
3. The amount of adding shrinking eliminating agents has important influence on eliminating the shrinkage defects of crankshaft specimens.

4. The optimal parameters were: No.3 shrinking eliminating agents $6 \mathrm{~g}$.

5. After adding No.3 shrinking eliminating agents, no abnormal graphite appears, the number of graphite increases significantly, and the ball diameter is smaller.

\section{REFERENCES}

[1] Sumio Kobayashi: J.Cryst.Growth. Vol.88 (1988).p.87-96.

[2] S. Ji, K. Reberts, Z.Fan. Scr Mater. 2006; 55: 971-974.

[3] R. D. Doherty, Ho-In. Lee, E.AFeest. Mater Sci Eng A. 1984; 65: 181-189.

[4] G.R. Ma,X.L. Li,L.Xiao,O.F. Li. J. Alloys Compd. 2010; 496: 577-581.

[5] L. Yan, C.S. Xie, L.L. Chen: Material \& Heat Treatment Vol.6 (2009), p. 95-98.

[6] J.M. Wu, S.L. Zheng, Z.Z. Li: Materials Review Vol.5 (1999), p.52-54. 